\title{
REDUÇÃO DE OCORRÊNCIA DE TRINCA NOS CILINDROS DE TRABALHO DO TREM ACABADOR DO LTQ-2 DA CSN*
}

Luiz Alberto Pereira Campbell ${ }^{1}$ Gilmar Procópio Ramos ${ }^{2}$ Alexandre de Sá ${ }^{2}$ Fabio de Oliveira Araujo ${ }^{3}$ Gilson Teixeira Cornelio ${ }^{4}$

\section{Resumo}

No processo de laminação a quente um dos fatores que afetam sua produtividade são os arrebentamentos de tira que ocorre no trem acabador, provocando paradas de longa duração, desvios de material e exposição do homem ao risco de acidentes. Dentro das causas responsáveis pelo arrebentamento de tira está o lascamento de cilindros de trabalho que é causado por trinca geradas na superfície do cilindro durante o processo de laminação. $O$ objetivo deste trabalho é identificar as possíveis causas dos lascamentos de cilindros de trabalho, propondo ações para reduzir as ocorrências utilizando o método solução de problemas. Após análise dos dados foi identificado que as ocorrências de falhas superficiais tinham forte correlação com as tensões de contato entre os cilindros de trabalho e o cilindro de encosto, foi realizado então um estudo com objetivo de verificar se as tensões de contato entre os dois cilindros poderiam estar relacionadas com os lascamentos. O método do estudo consistiu em simular diferentes perfis no cilindro de encosto (cilindro flat e com coroamento positivo) e diferentes caimentos (comprimento e altura) para obter os menores carregamentos possível. A condição de perfil e caimento com o menor carregamento foi testada no laminador para verificar na prática se houve a redução dos lascamentos. Os perfis e os caimentos testado permitiram uma redução significativa de ocorrência de lascamento de cilindros. A metodologia empregada para analise mostrou-se eficaz, podendo ser aplicada em outros laminadores para identificação de causas de falhas.

Palavras-chave: Cilindros; Falhas; Laminação a quente.

\section{REDUCTION OF WORK ROLLS CRACK OCCURRENCE IN THE FINISH STANDS AT} CSN HSM \#2

\begin{abstract}
In according to the hot rolling mill process, one of the main factors that affect productivity are the strip crash that occurs at the finishing stands in the HSM, causing production loosing, product deviations and human exposure to the accidents risk. Among the main causes for those failures, roll spalling which one is caused by superficial cracks on the work roll during the rolling process. The main objective of this paper is identify the possible causes for work roll spalling, by proposing actions to reduce barrel surface cracks using the failures analysis method. After analyzing all data it was identified bad conditions had been happened according to the contact stresses between the work rolls and back up roll, So it was made a study in order to verify if the contact stresses between the two rolls could be related to spalling. The research method was consisted to simulate different profiles at the back up roll (flat Roll and positive crown) and different stress relief tapers (length and height) to reach the lowest possible loading. The profile condition and taper with the lowest load was tested at the mill to verify by practicing if existed spalling reduction. The profiles and tested taper allowed significant reduction by the occurrence of spalling roll. The methodology used to this analysis was considered effective and it can be used to the other rolling mills to identify failures causes.

Keywords: Rolling mill rolls; Hot strip mill; Failure.

1 Eng. Metalurgista, Engenheiro Especialista da Gerência de Cilindros da Companhia Siderúrgica Nacional, RJ, Brasil.

2 Técnico Metalúrgico, Técnico de Desenvolvimento Especialista da Gerência de Cilindros da Companhia Siderúrgica Nacional, RJ, Brasil.

3 Eng. Metalurgista, Engenheiro Sênior da Gerência de Laminados a quente da Companhia Siderúrgica Nacional, RJ, Brasil.

4 Mestre em Eng. Mecânica, Engenheiro de Materiais, Gestor Técnico - Comercial de Villares Rolls, SP, Brasil.
\end{abstract}




\section{INTRODUÇÃO}

A indústria brasileira de transformação tem perdido competitividade, de forma contínua, há quase uma década, isto pode ser comprovado pela forte redução de sua participação no PIB, bem como pela perda de exportações de produtos manufaturados e pelo aumento do "Market Share", dos produtos importados, no consumo aparente de bens manufaturados no mercado brasileiro.

Um exemplo contundente vem da indústria siderúrgica, que segundo o Instituto Aço Brasil (IABr), há cerca de $25 \%$ de capacidade ociosa da indústria siderúrgica mundial. Diante do baixo custo do aço produzido na China, a importação de aço pelo Brasil tem crescido acima da produção interna. O resultado é que a indústria siderúrgica brasileira opera com $73 \%$ da capacidade, abaixo da média mundial.

Diante do contexto atual, o fator chave para a sobrevivência da indústria siderúrgica é a competitividade. Dentro dos fatores que são muito importantes para garantir a competitividade estão, a produtividade e a eficiência na hora de produzir.

O processo de produção de laminados a quente está em constante evolução na busca de melhoria de produtividade, um dos fatores que afetam sua produtividade são os arrebentamentos de tira que ocorre no trem acabador, provocando paradas de longa duração, desvios de produtos e exposição do homem ao risco de acidente.

Dentro das causas responsáveis pelo arrebentamento de tira está o lascamento de cilindros de trabalho que é causado geralmente por trincas geradas na superfície do cilindro durante o processo de laminação.

O objetivo deste trabalho é identificar as possíveis causas dos lascamentos de cilindros de trabalho, propondo ações para reduzir as ocorrências utilizando o método solução de problemas (MASP).

Foi realizado levantamento das ocorrências e após análise dos dados foi identificado que estas ocorrências tinham forte correlação com as tensões de contato entre os cilindros de trabalho e o cilindro de encosto, foi realizado então um estudo com objetivo de verificar se as tensões de contato entre os dois cilindros poderiam estar relacionadas com os lascamentos.

O método do estudo consistiu em simular diferentes perfis no cilindro de encosto (cilindro flat e com coroamento positivo) e diferentes caimentos (comprimento e altura) para obter os menores carregamentos possíveis.

A condição de perfil e caimento com o menor carregamento foi testada no laminador para verificar na prática se houve a redução dos lascamentos.

Os perfis e os caimentos testado permitiram uma redução significativa de ocorrência de lascamento de cilindros.

\section{MATERIAIS E MÉTODOS}

A metodologia empregada para identificar as possíveis causas dos lascamentos dos cilindros de trabalho foi o MASP - Método de Análise e Solução de Problemas, através da ferramenta PDCA, conforme mostra o quadro 1 abaixo: 
Quadro 1 - Fases do PDCA

\begin{tabular}{|l|l|l|}
\hline PDCA & \multicolumn{1}{|c|}{ FASE } & \multicolumn{1}{c|}{ OBJETIVO } \\
\hline \multirow{4}{*}{ P } & Identificação do problema & $\begin{array}{l}\text { Definir o problema e reconhecer sua } \\
\text { importância }\end{array}$ \\
\cline { 2 - 3 } & Observação & $\begin{array}{l}\text { Investigar as características específicas do } \\
\text { problema }\end{array}$ \\
\cline { 2 - 3 } & Análise & Descobrir as causas \\
\cline { 2 - 3 } & Plano de ação & Definir um plano para bloquear as causas \\
\hline \multirow{2}{*}{ D } & Execução & Bloquear as causas \\
\hline C & Verificação & Verificar se o bloqueio foi efetivo \\
\hline A & Padronização & Prevenir contra a reincidência do problema \\
\cline { 2 - 3 } & Conclusão & $\begin{array}{l}\text { Rever o processo utilizado para solucionar o } \\
\text { problema, para planejar possiveis melhorias }\end{array}$ \\
\hline
\end{tabular}

\subsection{Identificação do problema}

O problema foi identificado em meados do ano de 2009 e 2010 onde $0 \mathrm{n}^{\circ}$ de ocorrências de lascamento de cilindro de trabalho do LTQ-2 teve um aumento significativo em relação aos anos anteriores, conforme mostra o gráfico da figura 01.

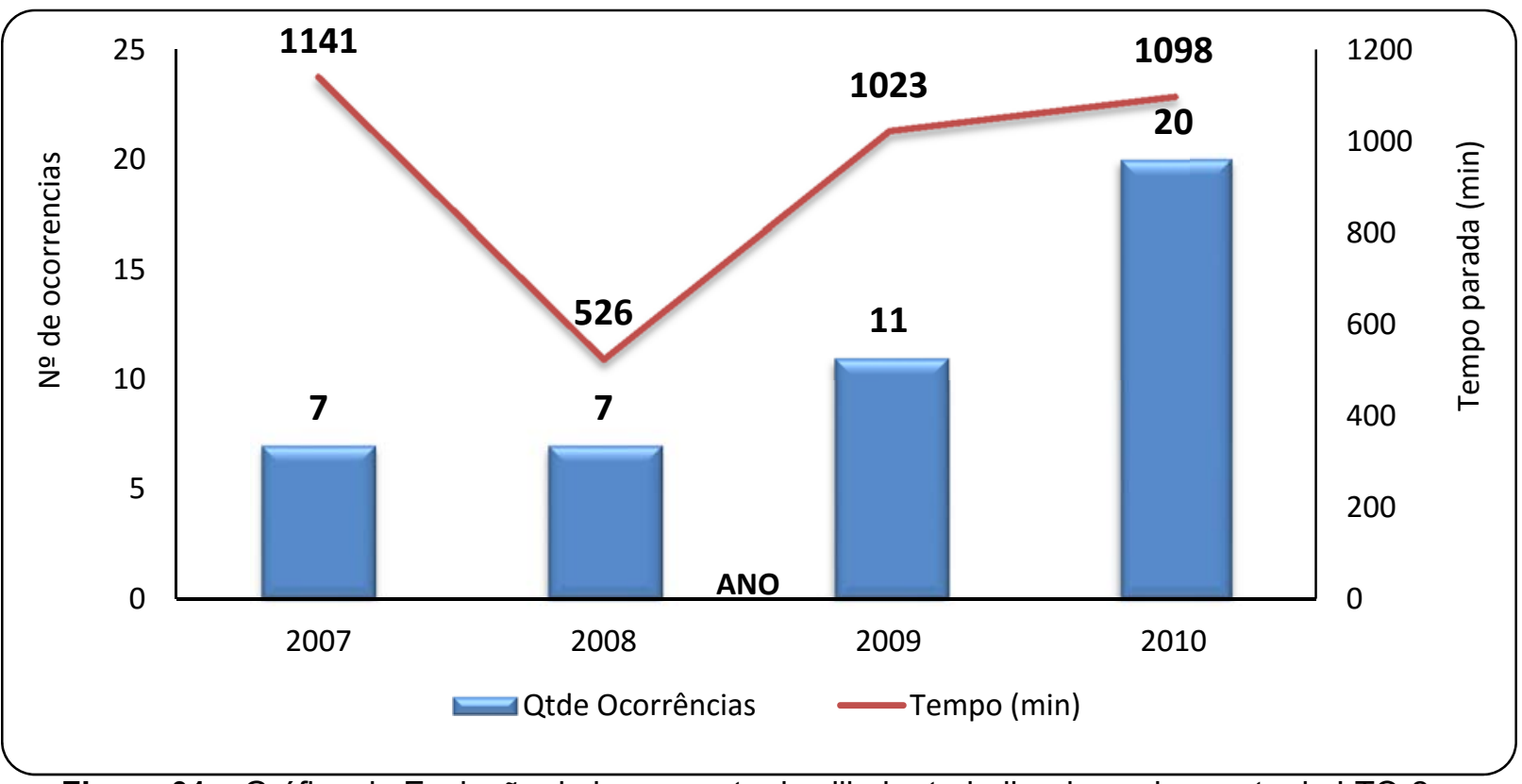

Figura 01 - Gráfico de Evolução de lascamento de cilindro trabalho do acabamento do LTQ-2

Foi realizado uma estratificação das ocorrências dos anos de 2009 e 2010 por cadeira, onde observa-se que $65 \%$ das ocorrências foram cadeiras F-5 a F-7, conforme mostra o gráfico da figura 02. 


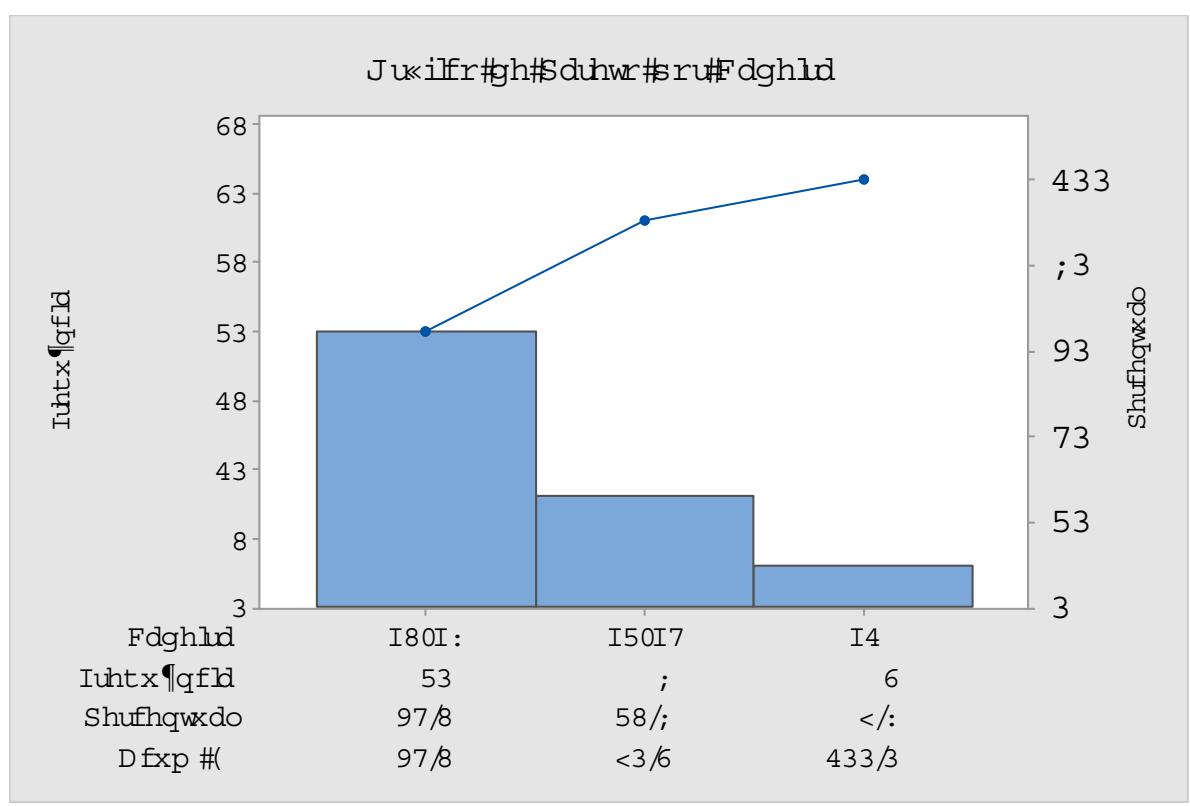

Figura 02 - Gráfico de Pareto de ocorrência por cadeira.

Estratificando as cadeiras F5 a F-7 temos que a maior incidência está nas cadeiras F5 e F-6, em torno de $85 \%$, como podemos observar no gráfico da figura 03.

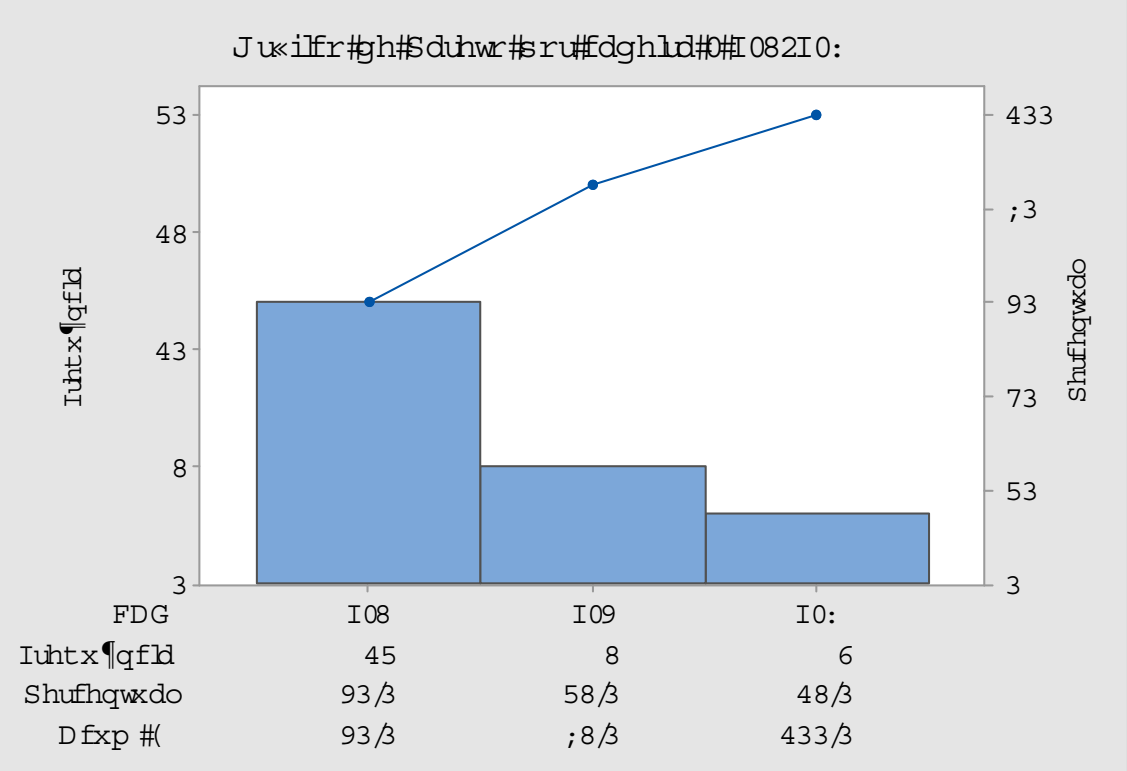

Figura 03 - Gráfico de Pareto das ocorrências das cadeiras F-5 a F-7.

Após as estratificações realizadas acima, concluímos que as ocorrências de lascamentos estão concentradas nas cadeiras F-5 e F-6, portanto o problema é ocorrência de lascamento nas cadeiras F-5 e F-6.

\subsection{Observação}

Nesta fase foi feito um levantamento das ocorrências das cadeiras F-5 e F-6, sendo listados todos os dados relevantes para analise, conforme mostra a tabela 1 
Tabela 1 - Levantamentos das ocorrências das cadeiras F-5/F-6 no ano de 2009 a 2010.

\begin{tabular}{|c|c|c|c|c|c|c|c|c|}
\hline $\begin{array}{c}\mathrm{N}^{\circ} \\
\text { Cilindro }\end{array}$ & Diâmetro & Data & Cad. & Pos. & $\begin{array}{c}\text { Tempo } \\
\text { Parada (min) }\end{array}$ & Causa & Lado & \begin{tabular}{|l} 
Dist. \\
Borda \\
\end{tabular} \\
\hline 59W509 & 734,70 & 09/06/09 & $F-6$ & $\mathrm{~T}$ & 162 & $\begin{array}{l}\text { Trinca na superfície da } \\
\text { mesa }\end{array}$ & LO & 560 \\
\hline $59 Y 426$ & 719,80 & $27 / 07 / 09$ & F-6 & B & 53 & $\begin{array}{c}\text { Trinca na superfície da } \\
\text { mesa }\end{array}$ & LM & 90 \\
\hline $59 Z 643$ & 725,10 & 04/01/10 & $F-5$ & B & 157 & $\begin{array}{l}\text { Trinca na superfície da } \\
\text { mesa }\end{array}$ & LM & 120 \\
\hline $59 Y 416$ & 717,20 & 04/01/10 & $F-5$ & $B$ & 0 & $\begin{array}{c}\text { Trinca na superfície da } \\
\text { mesa }\end{array}$ & LM & 120 \\
\hline $59 Z 496$ & 681,15 & 02/04/10 & $F-5$ & B & 91 & $\begin{array}{r}\text { Trinca na } \\
\mathrm{m}\end{array}$ & LO & 130 \\
\hline $59 Y 421$ & 703,55 & 03/04/10 & F-6 & B & 53 & $\begin{array}{l}\text { Trinca térmica de parada } \\
\text { de chapa devido sucata }\end{array}$ & LM & 800 \\
\hline $59 Y 552$ & 680,75 & 04/04/10 & $F-5$ & B & 60 & $\begin{array}{c}\text { Trinca na superfície da } \\
\text { mesa }\end{array}$ & LO & 130 \\
\hline 59Y557 & 684,70 & 05/04/10 & $F-5$ & B & 58 & $\begin{array}{c}\text { Trinca na superfície da } \\
\text { mesa }\end{array}$ & LO & 130 \\
\hline 59W515 & 713,81 & $22 / 04 / 10$ & F-6 & $\mathrm{T}$ & 67 & $\begin{array}{l}\text { Trinca na } \\
\text { mesa nã }\end{array}$ & LM & 330 \\
\hline $59 Z 606$ & 691,85 & 09/07/10 & $F-5$ & $\mathrm{~T}$ & 37 & $\begin{array}{c}\text { Trinca na superfície da } \\
\text { mesa }\end{array}$ & LO & 210 \\
\hline 59A005 & 689,55 & $22 / 07 / 10$ & $F-5$ & $\mathrm{~T}$ & 131 & $\begin{array}{c}\text { Trinca na superfície da } \\
\text { mesa }\end{array}$ & LO & 130 \\
\hline $59 Y 419$ & 715,20 & $13 / 08 / 10$ & F-6 & B & 39 & $\begin{array}{c}\text { Trinca na superfície da } \\
\text { mesa }\end{array}$ & LO & 630 \\
\hline $59 Z 470$ & 686,29 & $30 / 08 / 10$ & $F-5$ & $\mathrm{~T}$ & 65 & $\begin{array}{c}\text { Trinca na superfície da } \\
\text { mesa }\end{array}$ & LO & 130 \\
\hline $59 Z 487$ & 680,15 & 03/09/10 & $F-5$ & $\mathrm{~T}$ & 82 & $\begin{array}{c}\text { Trinca na superfície da } \\
\text { mesa }\end{array}$ & LO & 130 \\
\hline $59 Z 608$ & 697,95 & 26/09/10 & $F-5$ & B & 39 & $\begin{array}{c}\text { Trinca na superfície da } \\
\text { mesa }\end{array}$ & LM & 130 \\
\hline 59A002 & 686,00 & $19 / 10 / 10$ & $F-5$ & B & 16 & $\begin{array}{c}\text { Trinca na superfície da } \\
\text { mesa }\end{array}$ & LO & 120 \\
\hline $59 \vee 137$ & 679,70 & $05 / 11 / 10$ & $F-5$ & B & 70 & $\begin{array}{c}\text { Trinca na superfície da } \\
\text { mesa }\end{array}$ & LM & 130 \\
\hline
\end{tabular}

Com base nos dados da tabela 1 , foi feito o gráfico das ocorrências ao longo do tempo em ordem cronológica de data, conforme mostra a figura 04. 
Ocorrencia de lascamento de cilindros nas cadeiras F-5 e F-6

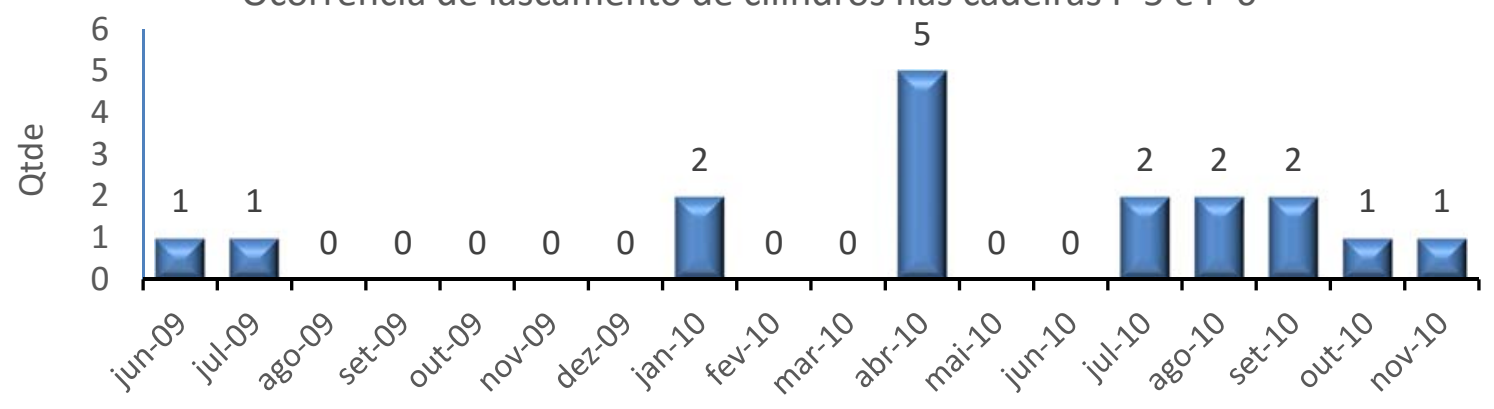

Figura 04- Gráfico das ocorrências ao longo do tempo.

O gráfico da figura 04 mostra que as ocorrências estão distribuídas ao longo dos meses, não estando concentradas em um mês especifico e que a partir do mês de julho/2010 houve um aumento da frequência com que ocorriam os lascamentos.

Foi realizado também estratificações das ocorrências por posição do cilindro na cadeira, lado e cadeira/distancia da borda do cilindro, os resultados estão apresentados nas figuras 05, 06 e 07 respectivamente.

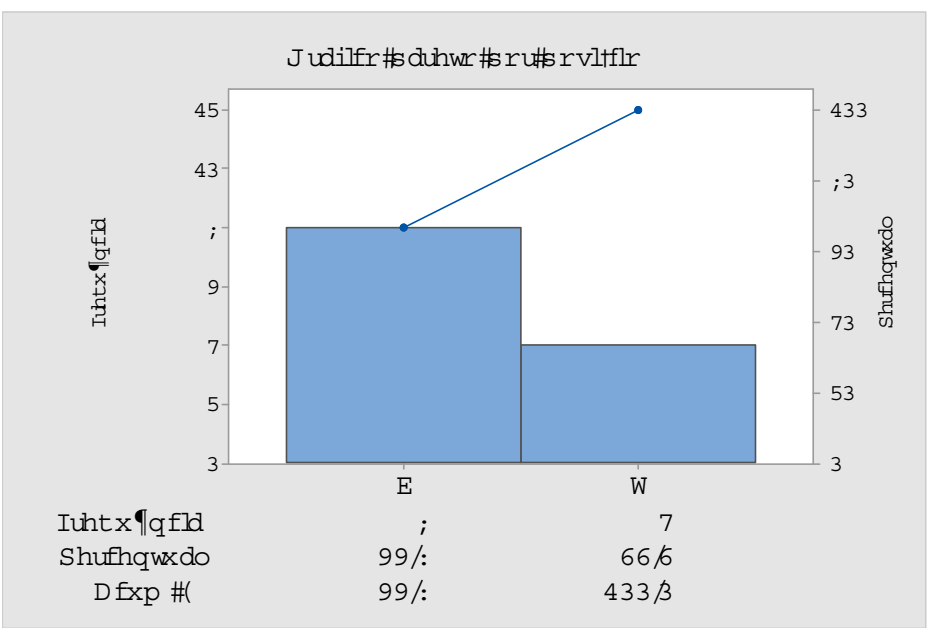

Figura 05- Gráfico de Pareto por posição

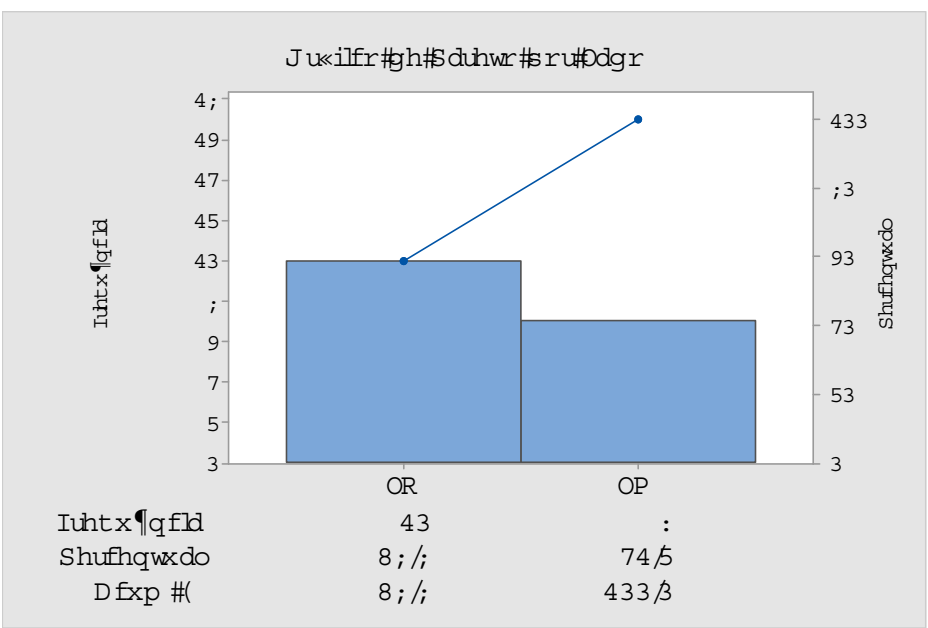

Figura 06- Gráfico de Pareto por lado. 


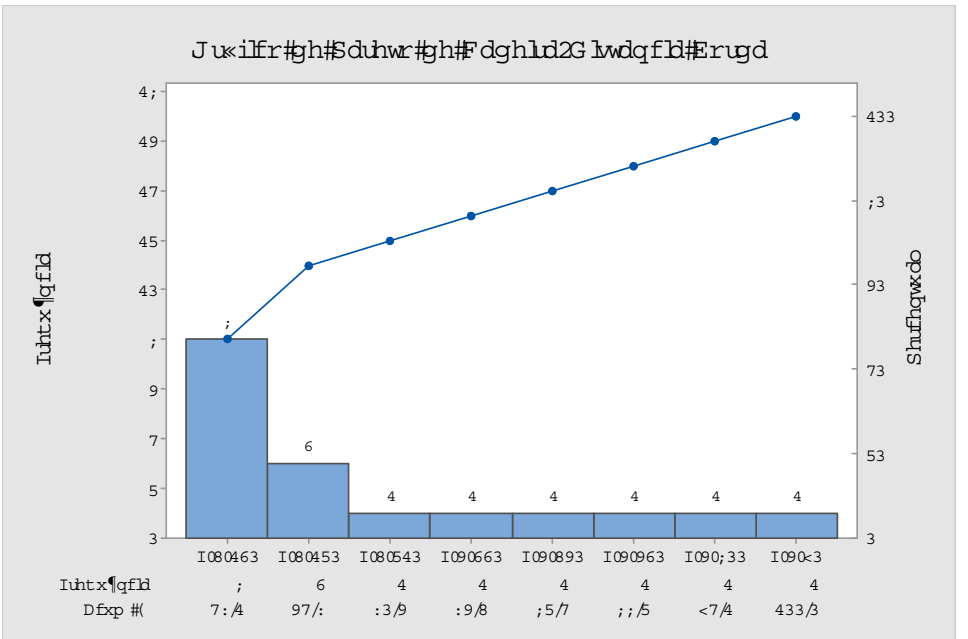

Figura 07- Gráfico de Pareto cadeira/distancia da borda do cilindro

Analisando os gráficos da estratificação das ocorrências de lascamento dos anos de 2009 e 2010 observamos que:

A. $65 \%$ dos lascamentos ocorreram nas ultimas cadeiras F-5 a F-7, sendo que mais da metade foi na cadeira F-5,

B. A maior incidência das ocorrências das cadeiras F-5/F-6 está na posição baixo $67 \%$,

C. Todos os lascamentos da cadeira F-5 tiveram como origem uma trinca na superfície da mesa, sendo que 10 ocorrências (60 \% total) foram no lado operação,

D. $65 \%$ dos lascamentos da cadeira F-5/F-6, o ponto inicial está distante 120 e 130 $\mathrm{mm}$ da borda da mesa do cilindro, sendo que 8 ocorrências (47\% total) foi a 130 $\mathrm{mm}$ da borda lado operação.

\subsection{Análise}

Com base nas conclusões da fase de observação, aonde as trincas que originam os lascamentos estão próximos a borda do cilindro de trabalho entre 120 e $130 \mathrm{~mm}$ de distância, temos verificar a região de contato entre o cilindro de encosto e o cilindro de trabalho na borda dos mesmos.

Analisando esta região de contato, observamos que as tensões de contato no cilindro de encosto máxima está no centro da mesa do cilindro quando o cilindro está novo, ou seja, no início de sua campanha no laminador e quando o cilindro sofre desgaste com seu uso na laminação, a tensão máxima está na borda do cilindro, conforme é ilustrado no desenho esquemático da figura 08. 


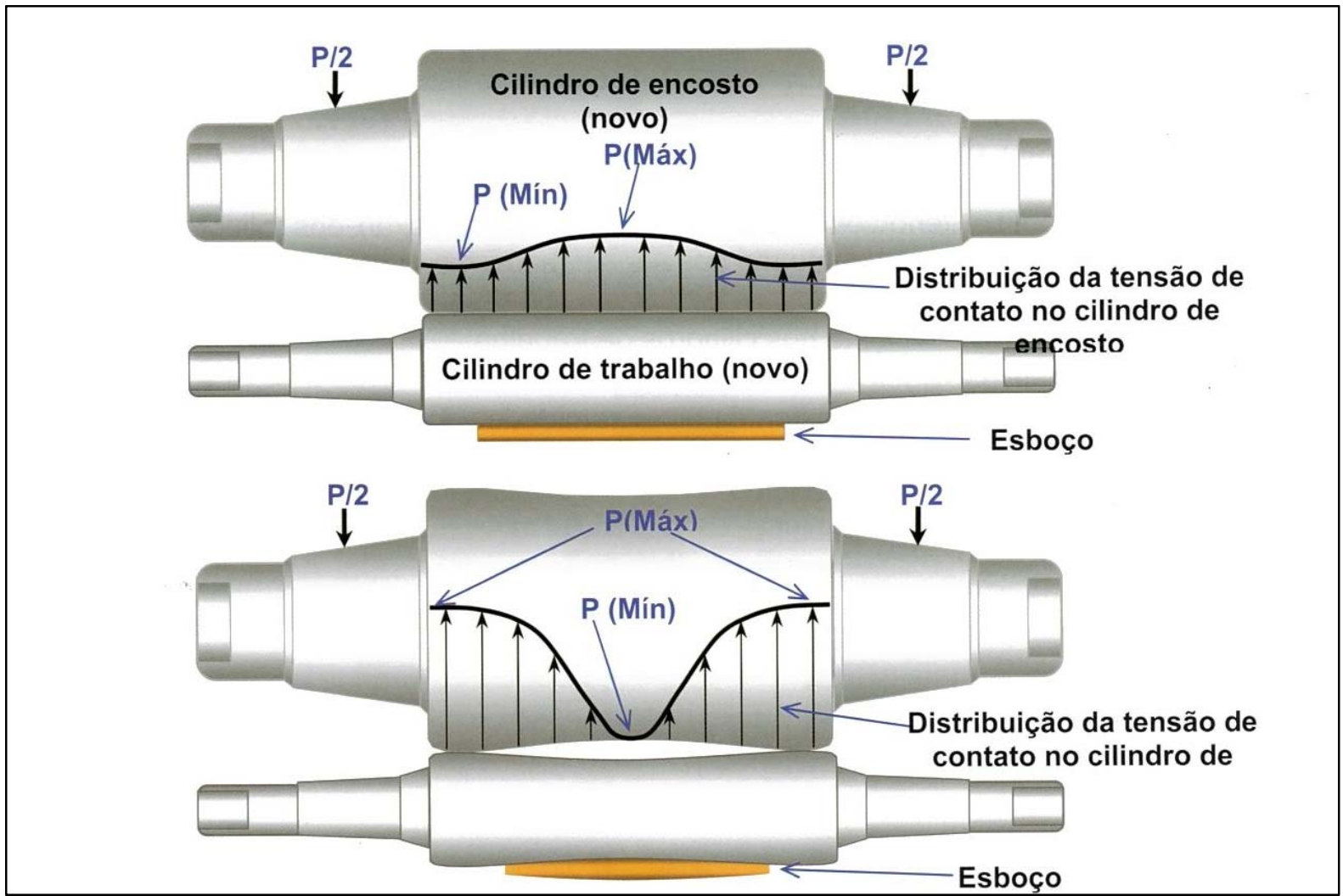

Figura 08 - Distribuição das tensões de contato no cilindro de encosto.

As trincas ocorrem numa região que está fora da área de laminação do material e coincide com a região do caimento do cilindro de encosto, justamente no ponto de maior concentração de tensão, conforme mostra o desenho esquemático da figura 09.

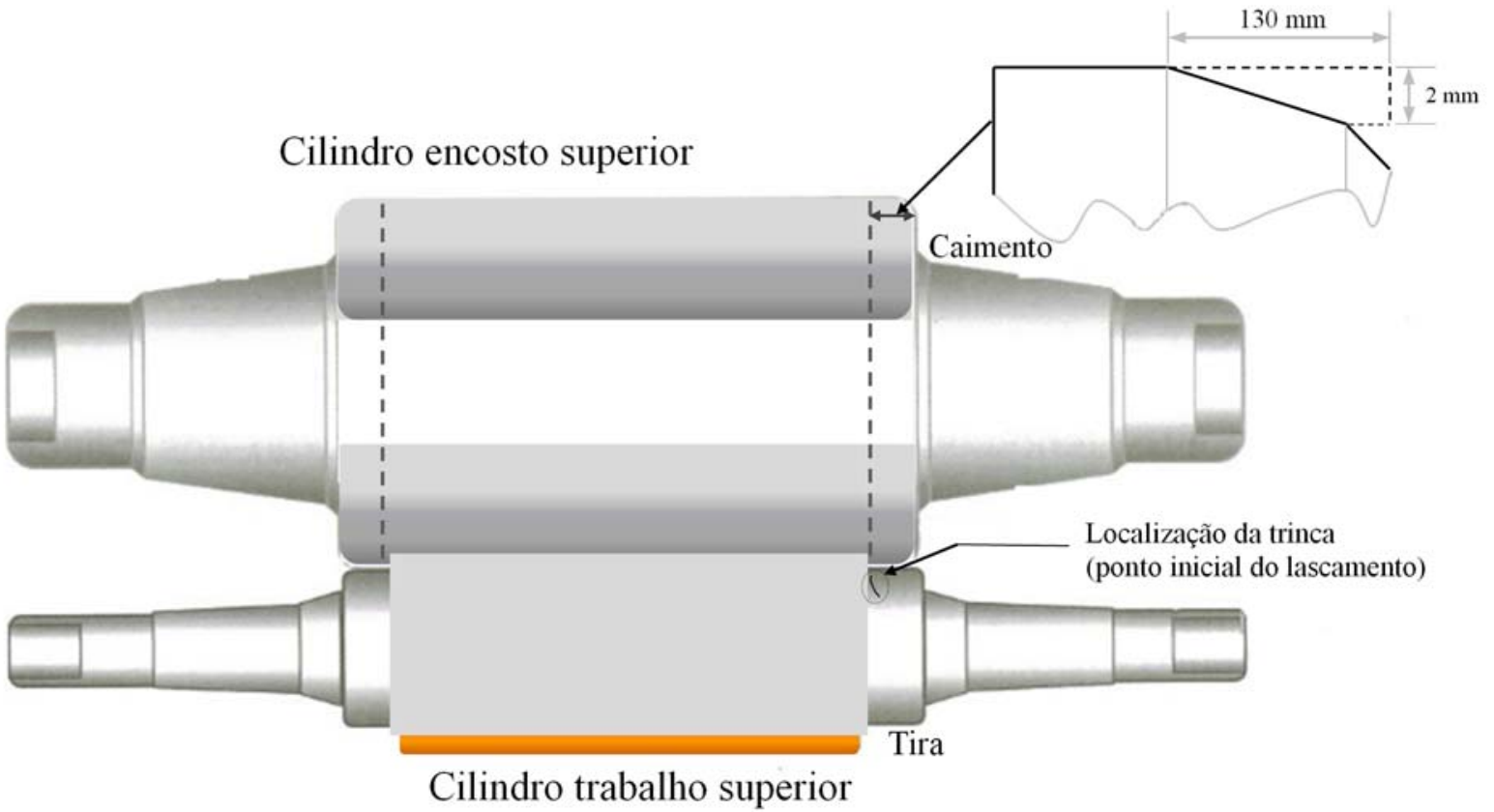

Figura 09 - Desenho esquemático da localização da trinca com caimento do encosto 
Baseado nas considerações acima as ocorrências de falhas superficiais tinham forte correlação com as tensões de contato entre os cilindros. Com isso, de modo a isolar essa condição, a otimização do caimento permitiria a condução de uma análise mais aprofundada da causa-raíz dessas falhas.

Com isso, foi realizado um estudo objetivando avaliar a correlação da nucleação e propagação das trincas geradoras dos lascamentos com o estado de tensões de contato entre os cilindros de encosto e de trabalho.

O método do estudo consistiu em simular diferentes perfis no cilindro de encosto, perfil cilíndrico e coroamento positivo, e diferentes caimentos, variando-se o comprimento e a altura, para otimizar a distribuição da pressão ao longo do comprimento de contato entre os cilindros.

Após essa avaliação e definição ótima da condição desse perfil, incluindo o caimento, foi realizado um protótipo de teste para a operação no laminador, para validar os resultados.

Para a construção desse estudo, foi considerado o cilindro de trabalho da cadeira F-5, utilizando-se uma coroa negativa com amplitude de $0,10 \mathrm{~mm}$, também para o caso da cadeira F-7, não sendo adotado coroamento, perfil cilíndrico. O cilindro de encosto, para ambas cadeiras, assumiu também um coroamento nulo, incluindo um caimento de $130 \mathrm{~mm}$ de comprimento e $2 \mathrm{~mm}$ altura.

Para essa avaliação, o estudo se baseou no método das diferenças finitas, fazendo-se uso de um aplicativo de simulação computacional denominado ROLLFLEX®, com o qual são construídos os modelos geométricos e carregados dados da laminação e propriedades dos cilindros. Na cadeira F-5 verificou-se região sem contato (carga 0) na região do caimento para o perfil de distribuição de carga em cilindro NOVO (sem desgaste) conforme mostra a figura 10.

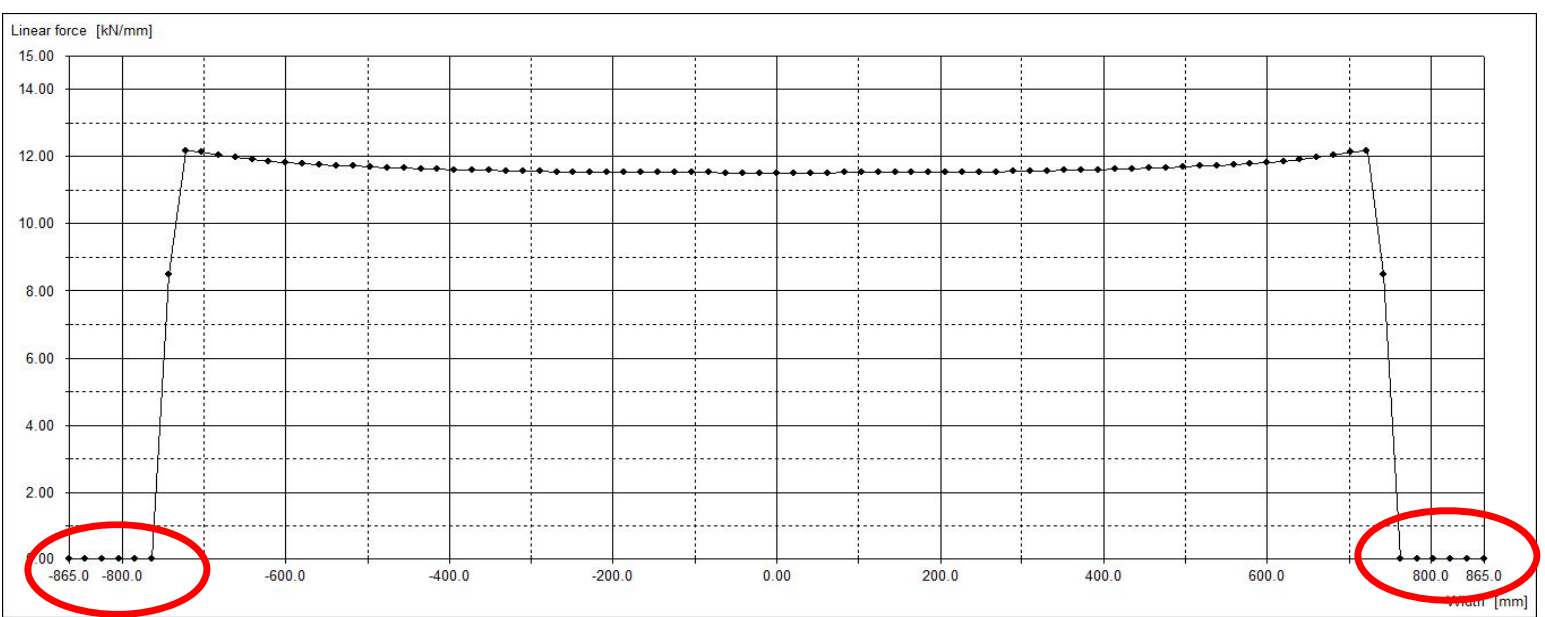

Figura 10 - Distribuição de carregamento linear no cilindro de encosto cadeira F-5

A figura 11 mostra o detalhe da distribuição de carregamento linear no cilindro de encosto na cadeira F-5, considerando o perfil inicial dos cilindros de trabalho e encosto sem desgaste. Os valores máximos de carregamento nas bordas do contato Encosto/Trabalho ( $12,2 \mathrm{kN} / \mathrm{mm})$ e o valor mínimo de carregamento no centro $(\sim 11,5$ $\mathrm{kN} / \mathrm{mm})$. 


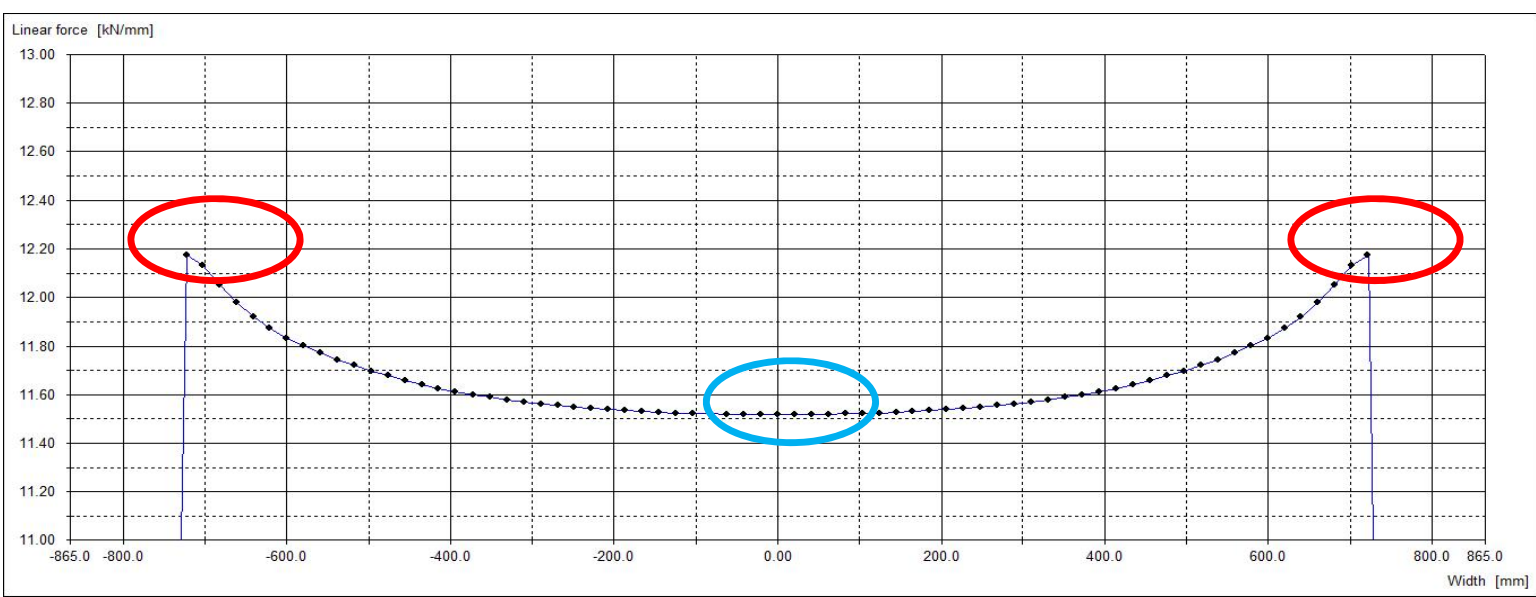

Figura 11 - Detalhe da distribuição de carregamento linear no cilindro de encosto cadeira F-5

Na cadeira F-7 verificou-se região sem contato (carga 0 ) na região do caimento para o perfil de distribuição de carga em cilindro NOVO (sem desgaste) conforme mostra a figura 12.

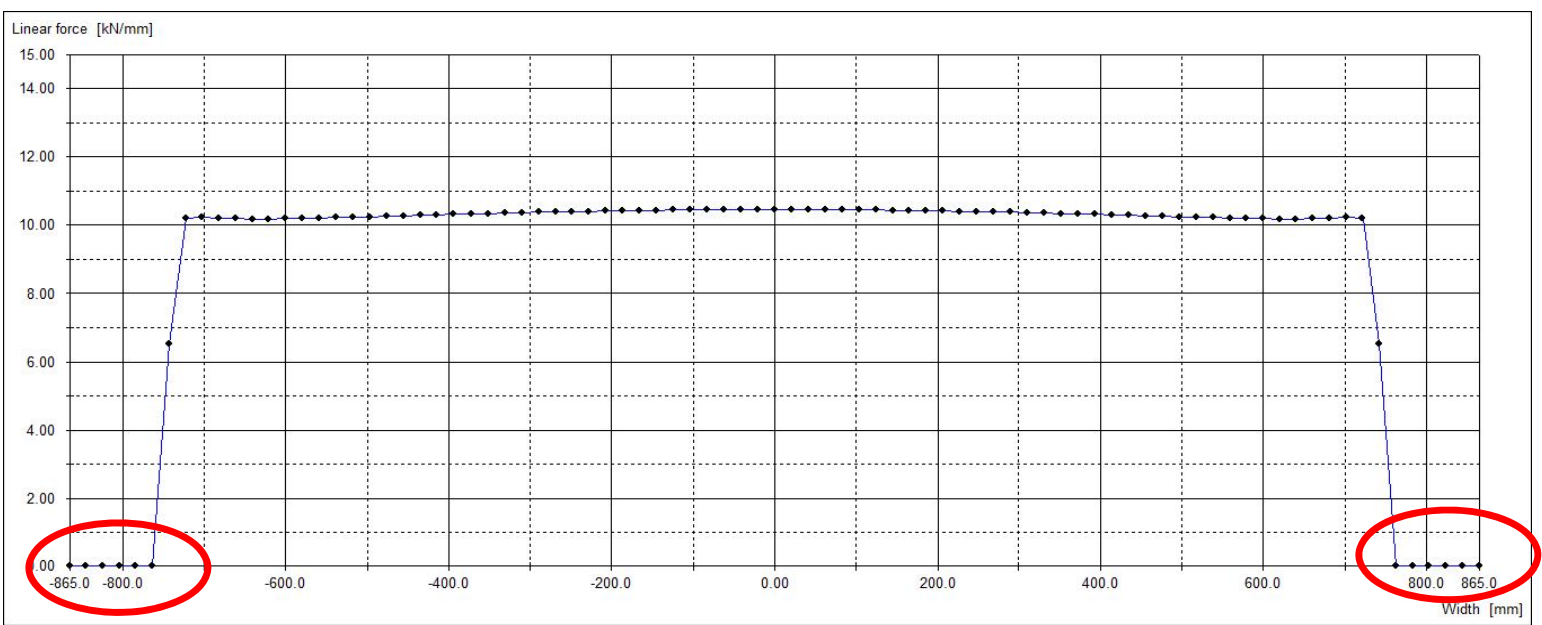

Figura 12 - Distribuição de carregamento linear no cilindro de encosto cadeira F-7

A figura 13 mostra o detalhe da distribuição de carregamento linear no cilindro de encosto cadeira F-7 considerando perfil inicial dos cilindros de trabalho e encosto (sem desgaste). A concentração de carregamento linear no centro do contato do encosto/trabalho $(\sim 10,45 \mathrm{kN} / \mathrm{mm})$ e inflexão de carregamento linear próximo à borda de contato. 


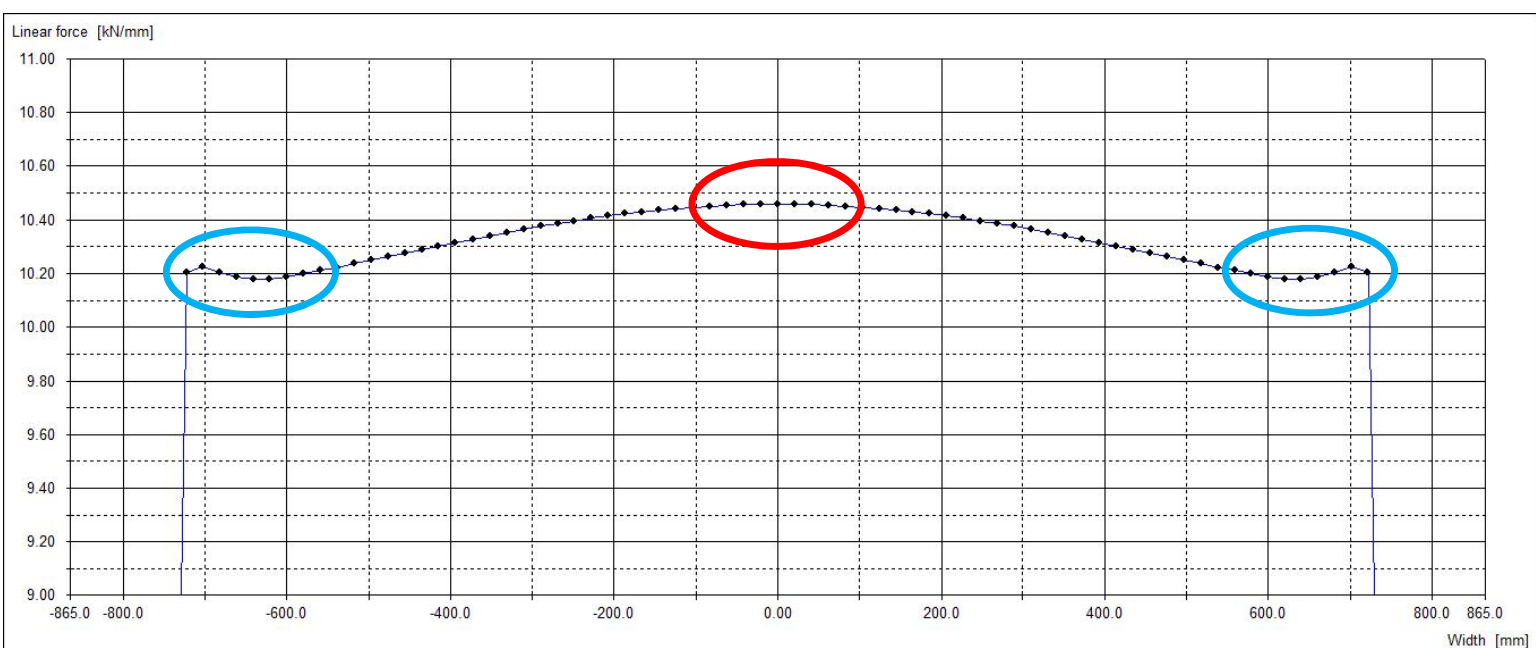

Figura 13 - Detalhe da distribuição de carregamento linear no cilindro de encosto cadeira F-7

Para simulação do caimento do cilindro de encosto foi propostos as seguintes dimensões: $100 \times 1 \mathrm{~mm}, 100 \times 3 \mathrm{~mm} ; 130 \times 1 \mathrm{~mm}, 130 \times 3 \mathrm{~mm}$ e os resultados esta ilustrado na figura 14 para cadeira F-5 e na figura 15 para a cadeira F-7.

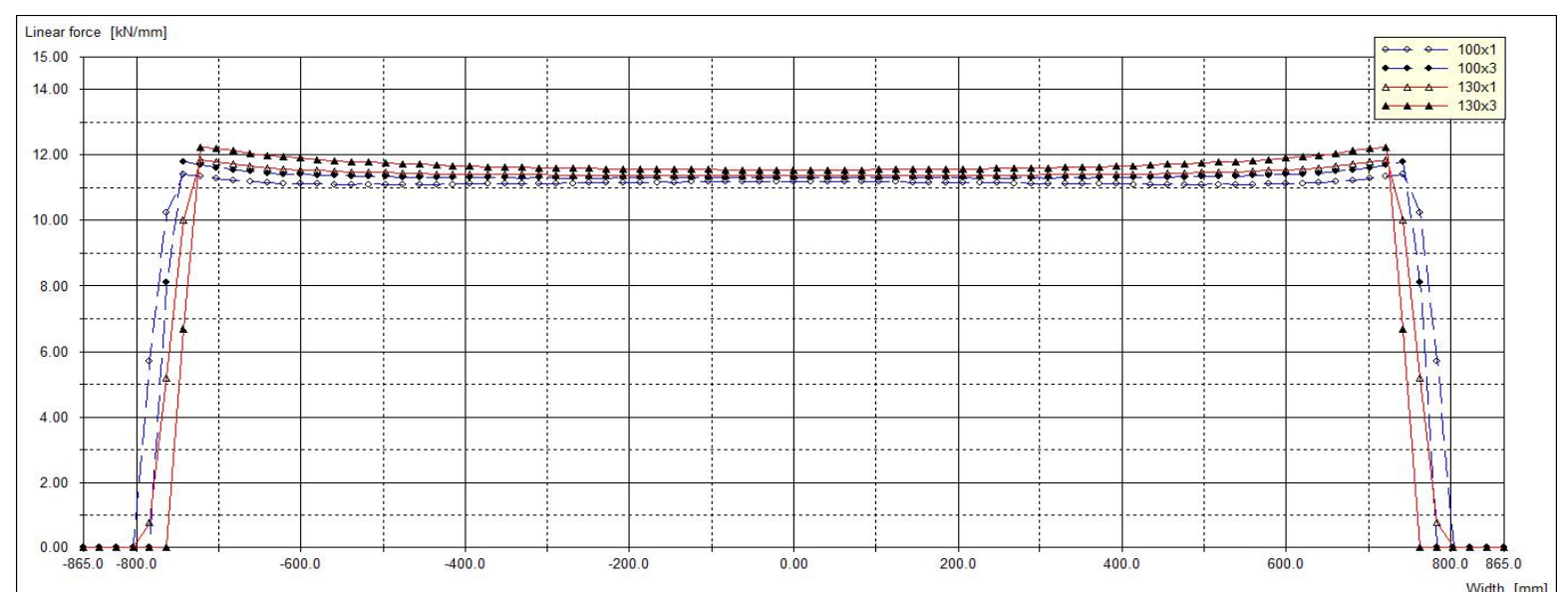

Figura 14 - Distribuição de carregamento linear no cilindro de encosto cadeira F-5 para diferentes caimentos

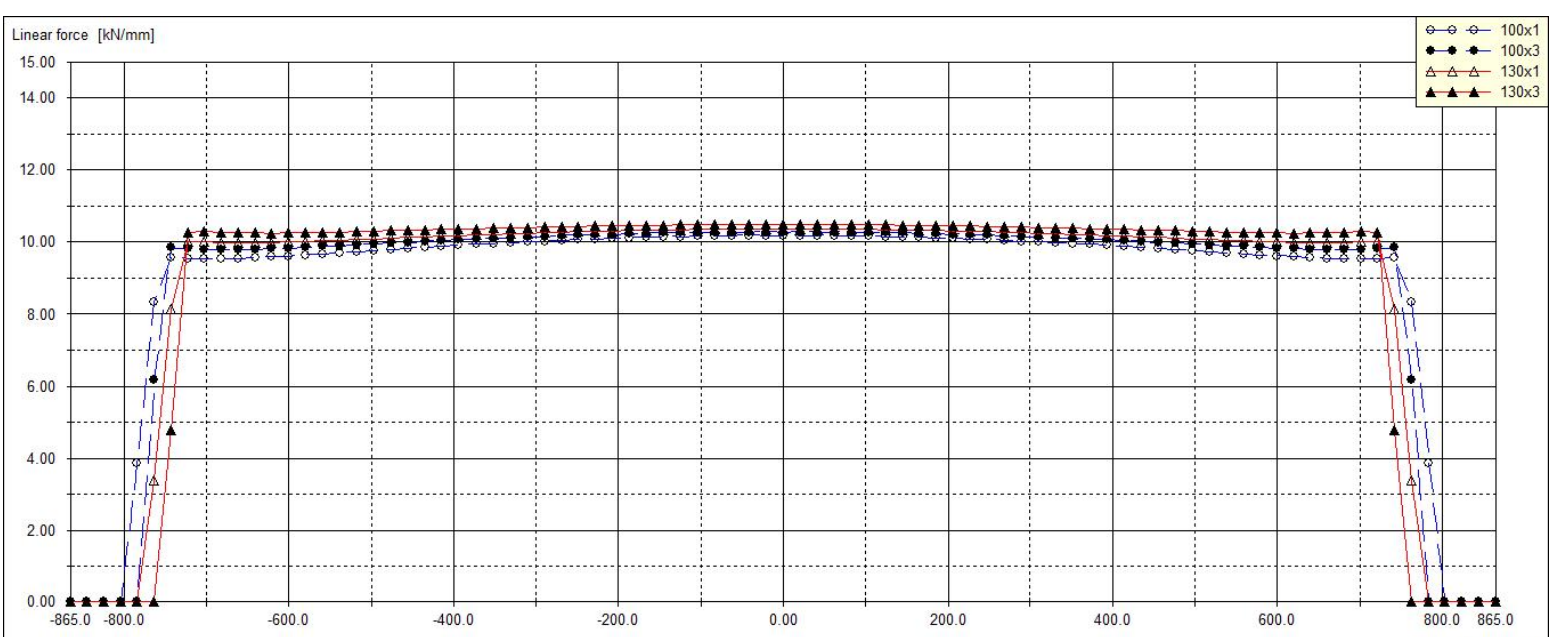

Figura 15 - Distribuição de carregamento linear no cilindro de encosto cadeira F-7 para diferentes caimentos 
Considerando perfil inicial dos cilindros de trabalho e encosto (sem desgaste), verificou-se a influência da alteração do caimento na distribuição de carregamento linear no cilindro de encosto.

Para a cadeira F-5 foi observada uma redução de $7 \%$ do carregamento linear na borda de contato do cilindro de encosto, com a redução do caimento (aumento do comprimento de contato encosto/trabalho), vide figura 16.

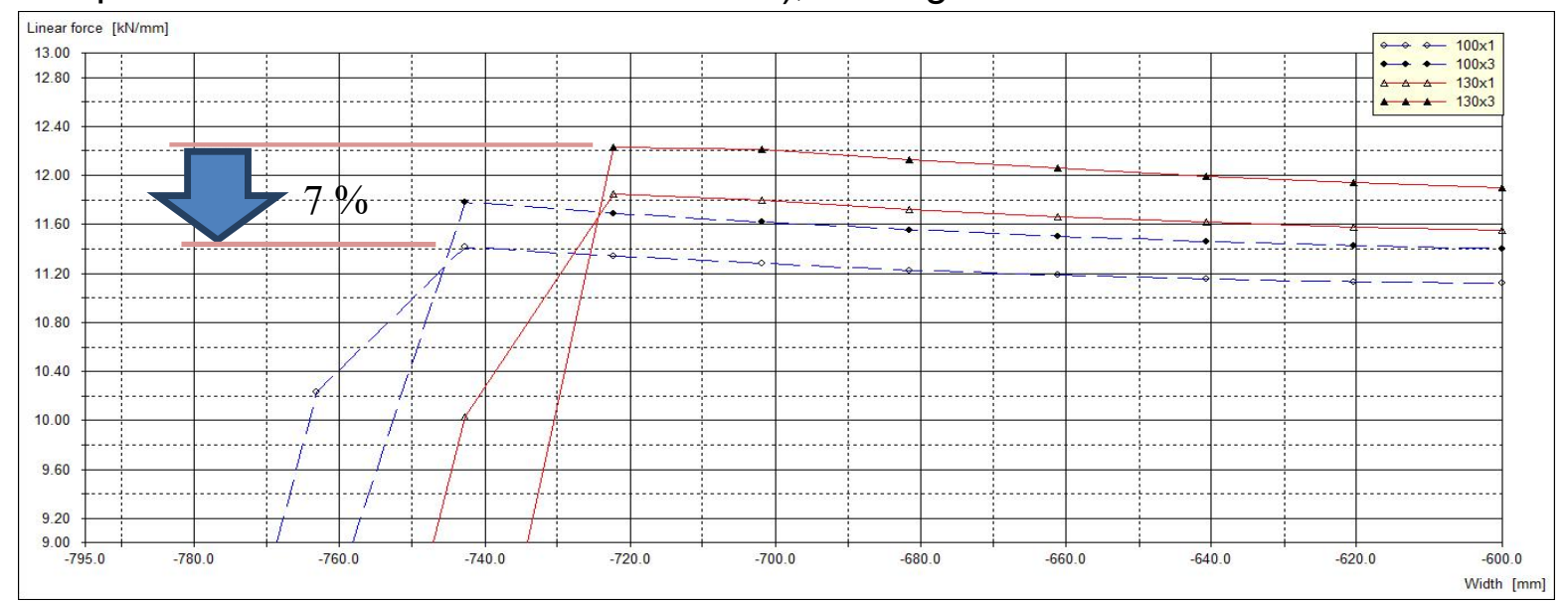

Figura 16 - Detalhe na borda de contato para cadeira F-5

O modelo adotado, incluindo geometrias dos cilindros, seus perfis/coroamentos e carregamento mostraram perfis de carregamento coerentes com as condições esperadas, entretanto, referem-se à condição do cilindro em início de vida.

Com uma análise prévia, verifica-se que é possível otimizar o carregamento linear de contato a partir da alteração do caimento do cilindro de encosto.

\subsection{Execução}

Depois de realizado o estudo foi feito as simulações para analise das tensões de contato por elementos finitos, conforme mostra o diagrama da figura 17.

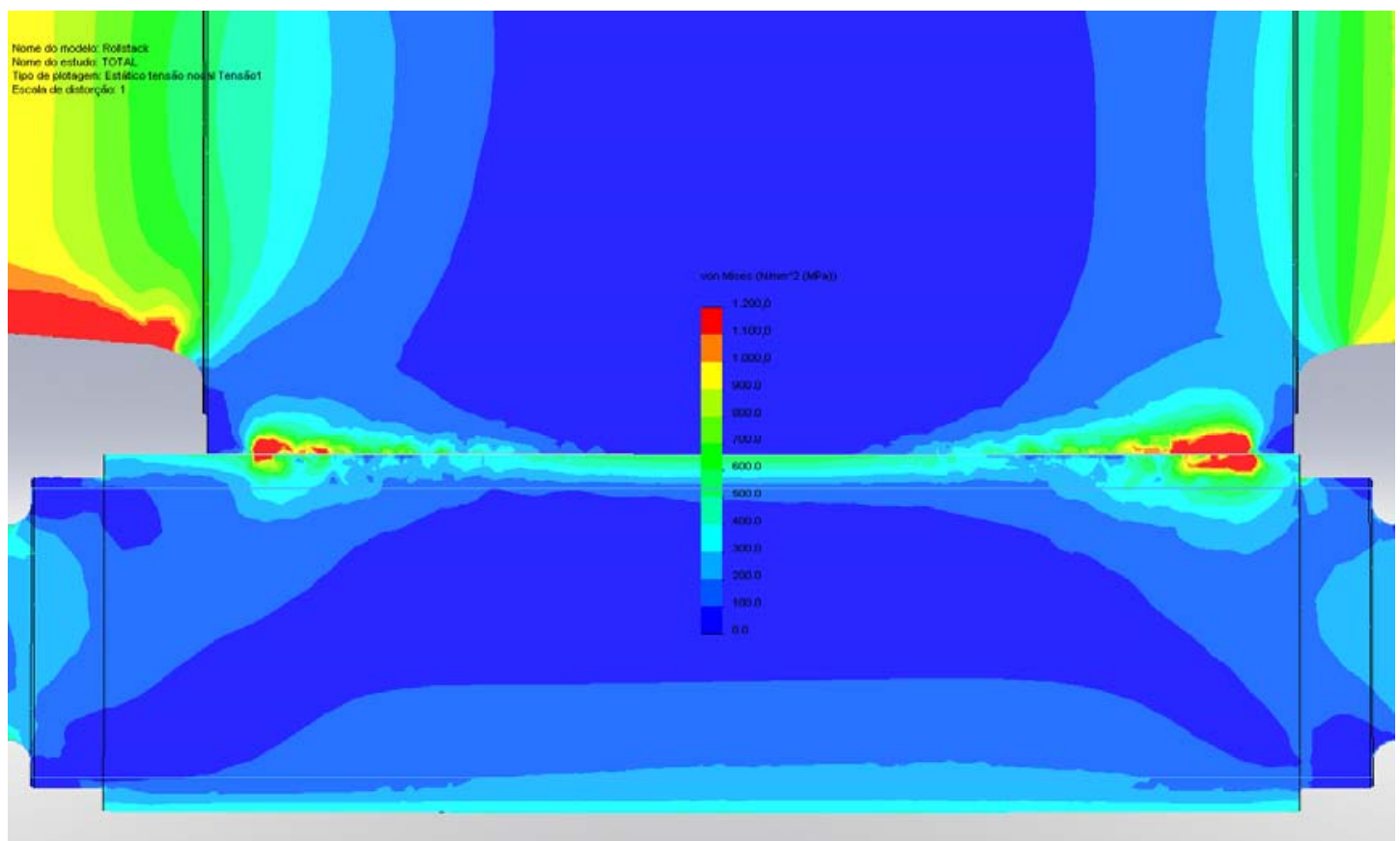

Figura 17 - Tensões de contato entre cilindro de encosto/trabalho 
Considerando coroamento no cilindro de encosto de $+0,10 \mathrm{~mm}$ e o caimento de $130 \mathrm{x}$ 2 e $100 \times 1$ ) os resultados estão nos gráficos da figura 18 e figura 19.

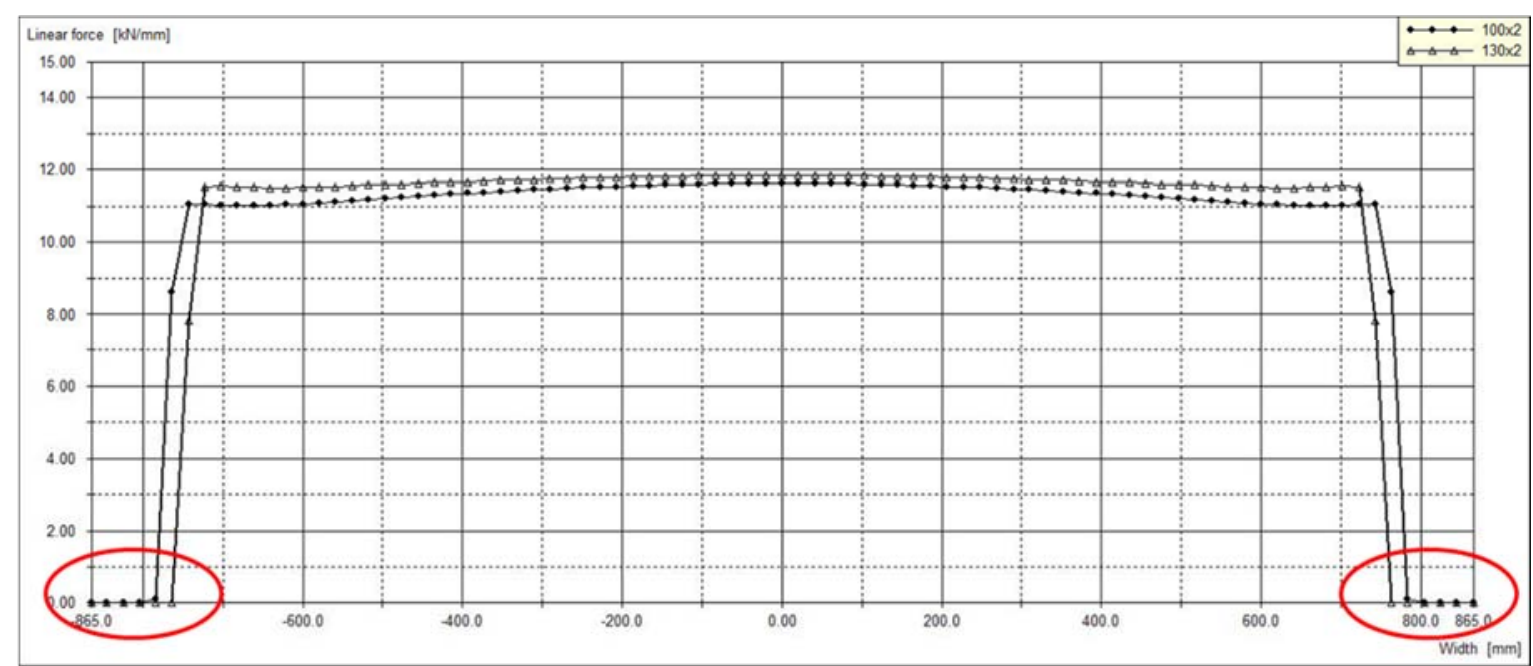

Figura 18 - Distribuição de carregamento linear no cilindro de encosto cadeira F5

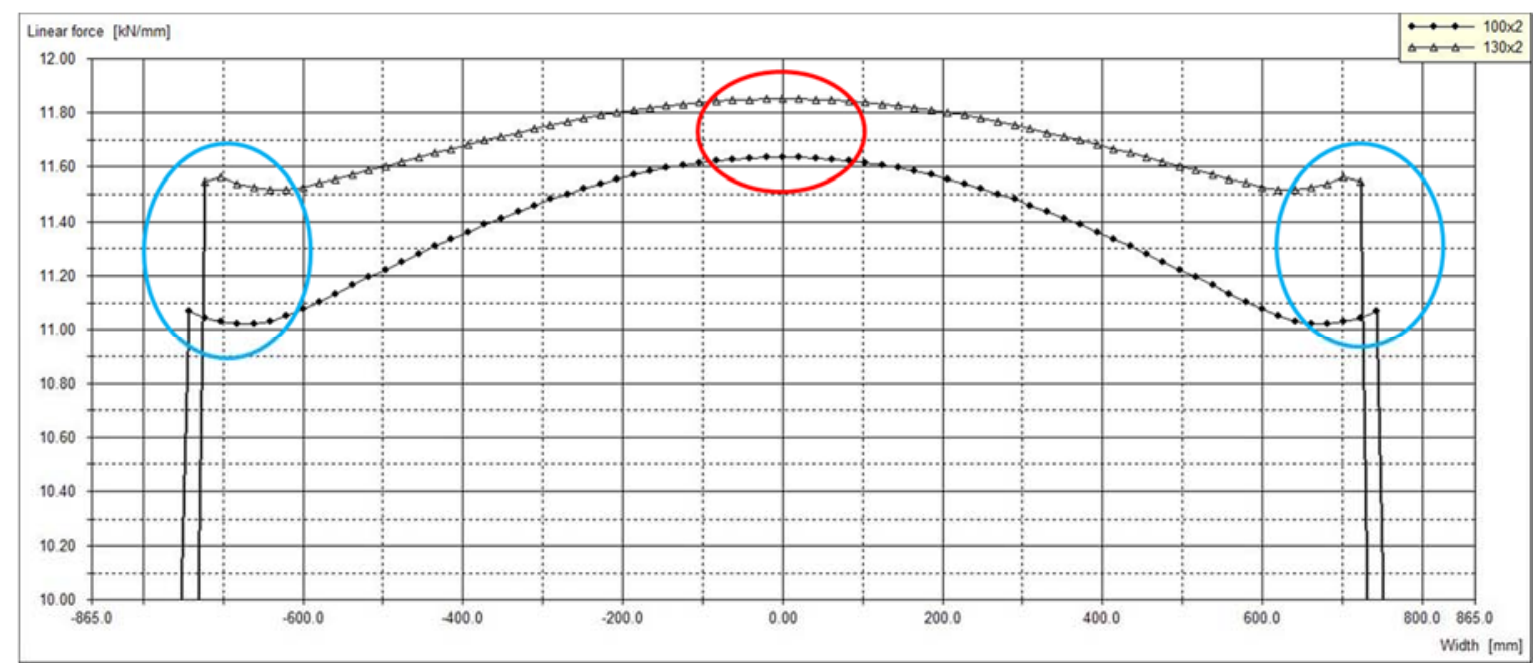

Figura 19 - Detalhe da distribuição de carregamento linear no cilindro de encosto cadeira F5

Os resultados obtidos para coroamento no cilindro de encosto de $+0,20 \mathrm{~mm}$ e 0 caimento de $130 \times 2$ e $100 \times 1$, estão nos gráficos da figura 20 e 21

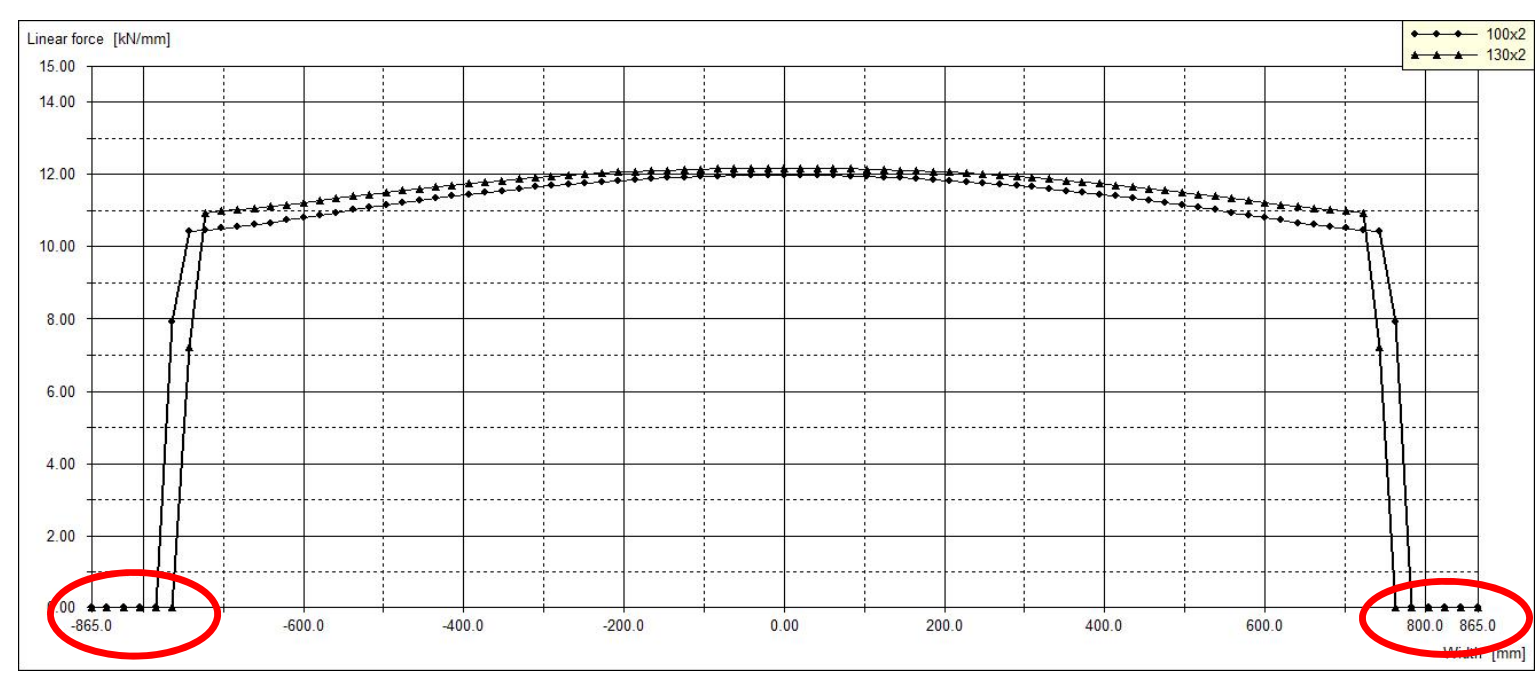

Figura 20 - Distribuição de carregamento linear no cilindro de encosto cadeira F5 


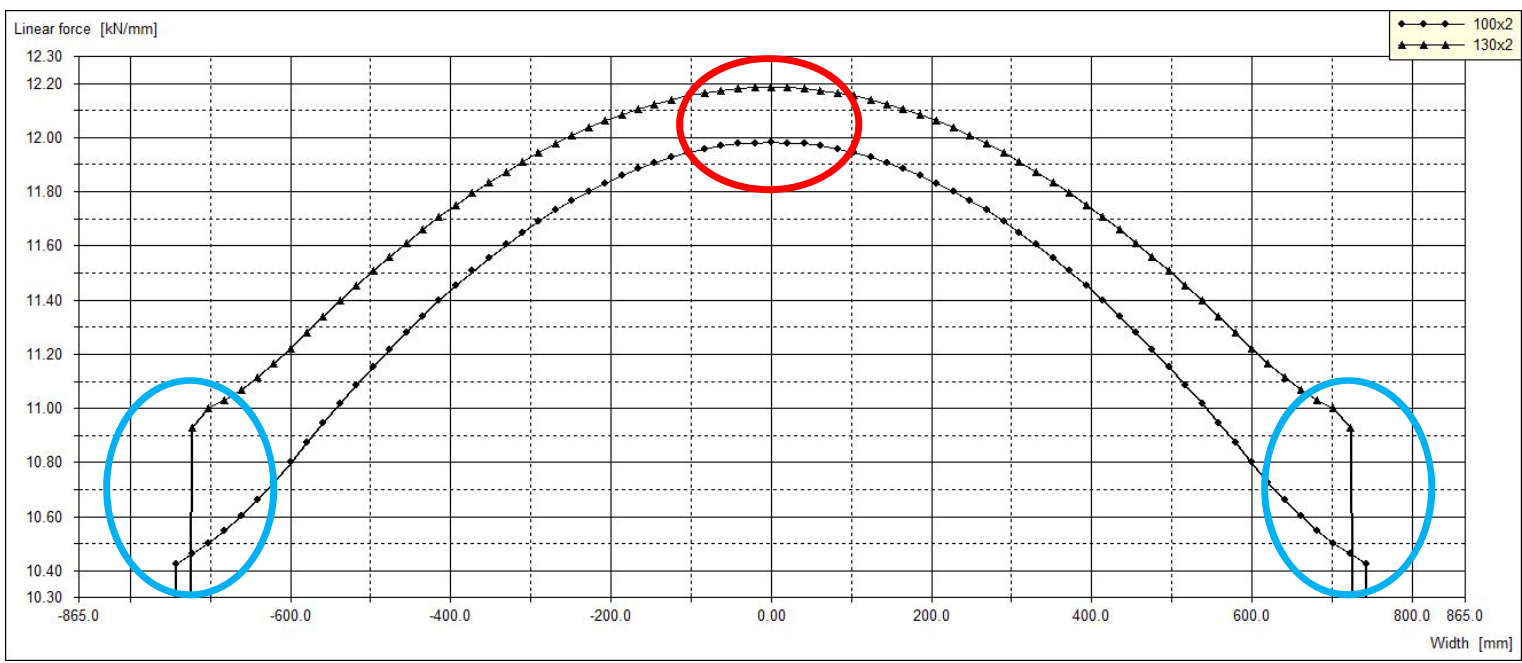

Figura 21 - Detalhe da distribuição de carregamento linear no cilindro de encosto cadeira F5

Baseado nos resultados das simulações realizadas foi optado por implantar a solução que apresentou menor carregamento, ou seja, a coroa de $+0,20 \mathrm{~mm}$ e o caimento de $100 \mathrm{~mm} \times 1 \mathrm{~mm}$ no cilindro de encosto.

\section{VERIFICAÇÃO}

Após a implantação da solução proposta houve uma redução significativa de ocorrências de lascamento de cilindro trabalho, conforme mostra o gráfico a figura 22 abaixo.

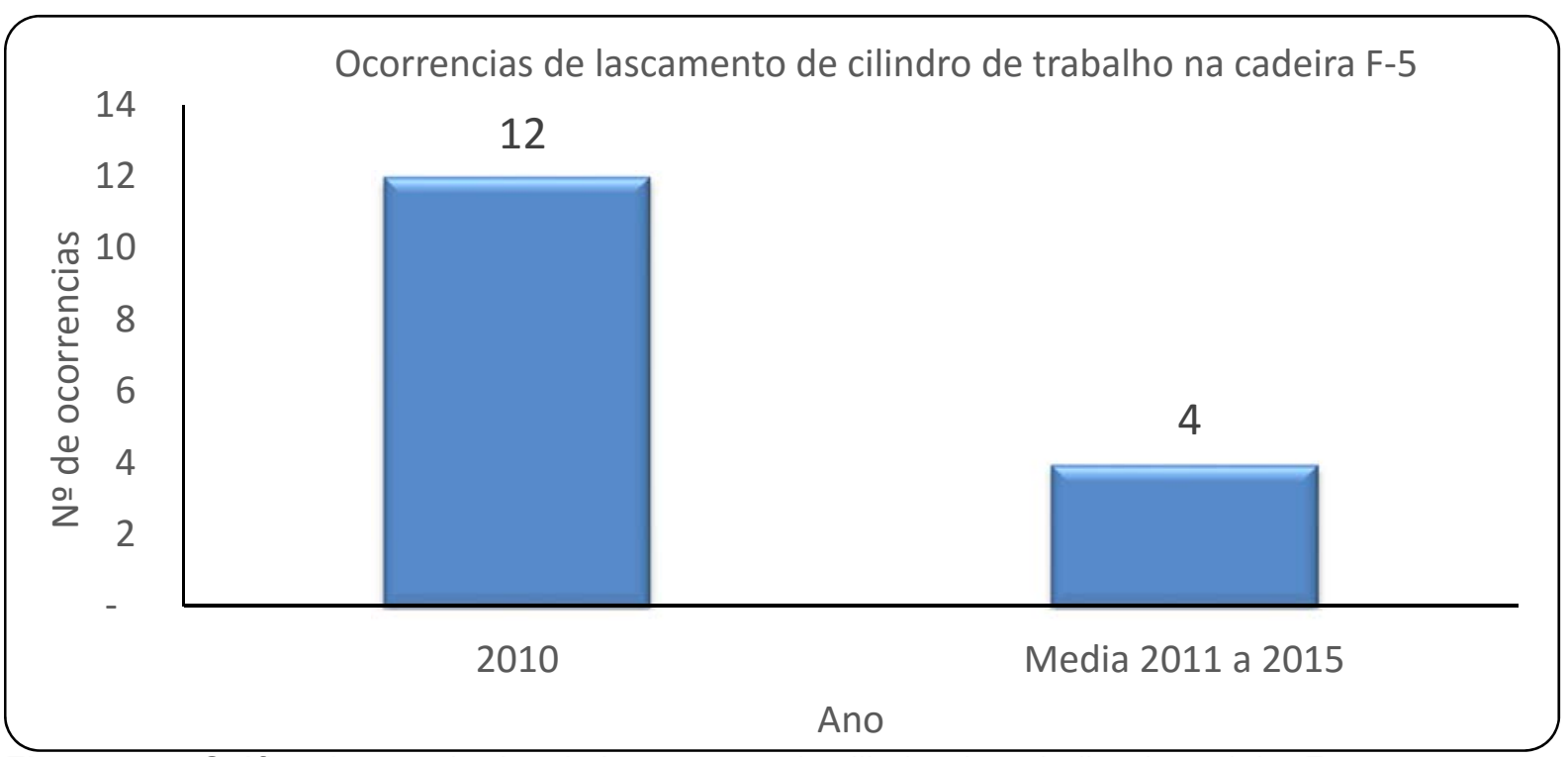

Figura 22 - Gráfico de ocorrências de lascamento de cilindro de trabalho da cadeira F-5

\section{RESULTADOS}

A alteração do coroamento e do caimento do cilindro de encosto possibilitaram uma redução na perda de vida útil de cilindro em 68 \% conforme mostra o gráfico da figura 23 e redução de $74 \%$ no tempo de parada do laminador conforme gráfico da figura 24. 


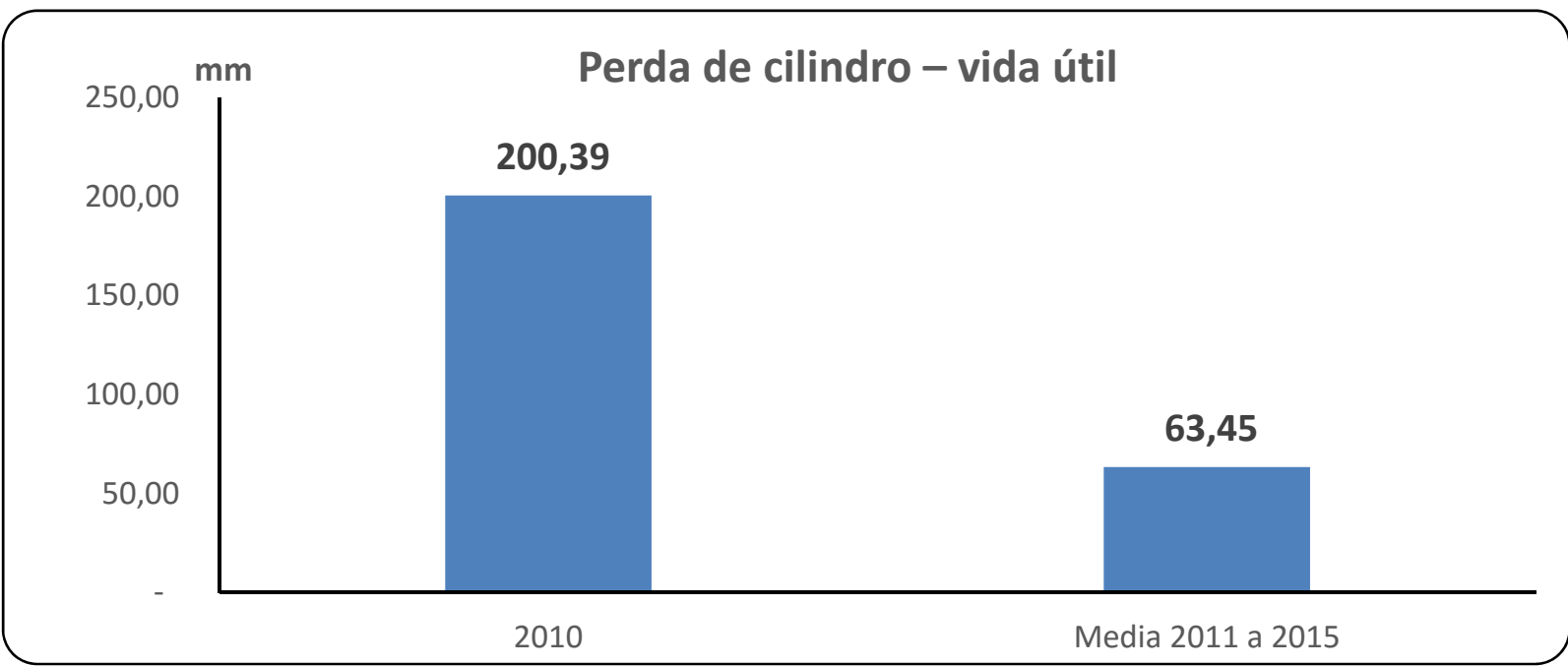

Figura 23 - Gráfico de perda de vida útil de cilindro

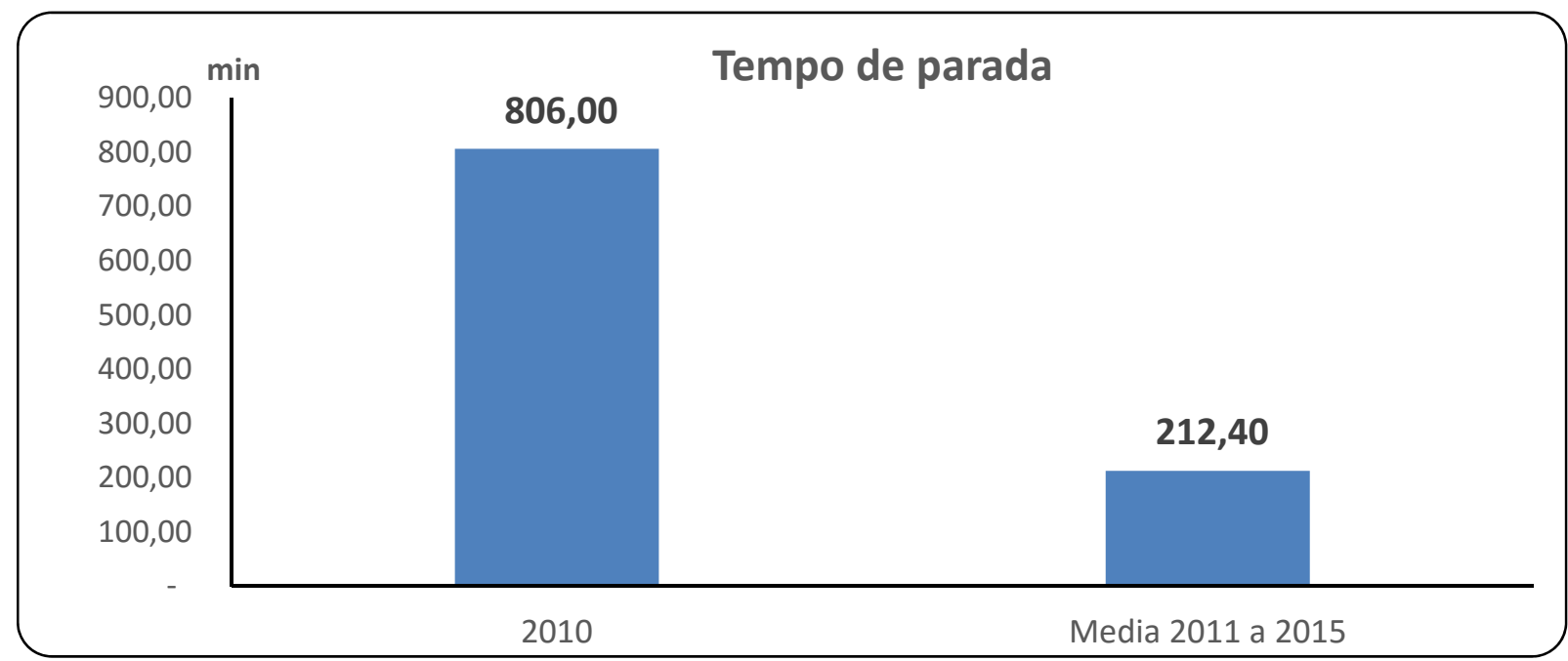

Figura 24 - Gráfico do tempo de parada do laminador

\section{BENEFÍCIOS}

Os benefícios alcançados com este trabalho, a redução da perda de vida útil do cilindros e redução do tempo de parada do laminador, proporcionaram um ganho anual significativo.

Outros benefícios obtidos foram:

- Segurança - Redução da ocorrência de sucata no laminador, como consequência menor exposição do homem ao risco.

- Meio ambiente - Redução da geração sucata de cilindro devido a redução do lascamento de cilindro.

\section{CONCLUSÕES}

Com a implantação da proposta houve uma redução significativa de ocorrência de lascamento de cilindros, em torno $67 \%$ nos últimos 5 anos.

A metodologia empregada para analise mostrou-se aderência dos resultados em operação com o processo de simulação computacional, podendo ser aplicada em outros laminadores para identificação de causas de falhas. 
Como continuidade para esse estudo, sugere-se o uso de perfis desgastados dos cilindros, para avaliar a influência da perda de contato entre os cilindros na concentração da pressão de contato. Para tanto, é necessário um levantamento estatístico desses perfis com as novas condições em uso.

\section{REFERENCIAS}

1 Hajduk, D., Simecek, P., Rebellato, M.A., Cornelio, G.T. Fatigue of backup rolls, lenght of campaign and dressing amount. ABM: São Paulo, 2007.

2 Cornelio, G., Murad, B.B.S., Guarda, A.A.S., Serantoni, C.R., Tavares, M.C.G. Estudo de extensão de campanha do laminador de tiras a quente da ArcelorMittal Tubarão. ABM: $49^{\circ}$ Seminário de laminação. Vila Velha, ES. 2012.

3 Hajduk, D., Cornelio, G. T., Bernardes, F. G. Computer modelling for better BuR performance. 46 Rolling Seminar. ABM. Santos, Brazil. 2009.

4 ITA Ltd.: Software Rollflex. Consulta internet: [http://www.ita-tech.cz/en/products-services/rolling/profile-and-flatness/rollflex-software].

5 CAMPOS, Vicente Falconi. Gerenciamento da rotina do trabalho do dia-a-dia. Nova Lima: INDG Tecnologia e Serviços Ltda., 2004. 